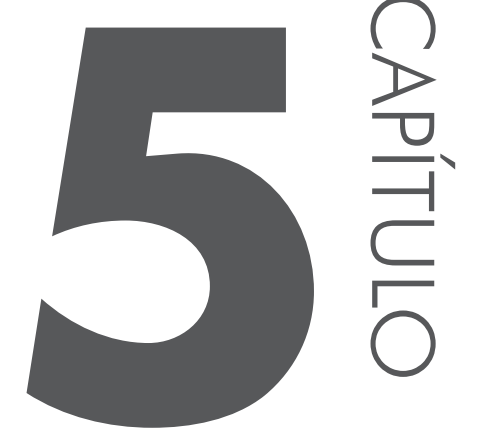

\title{
A poesia como a pintura
}

Álvaro Cardoso Gomes ${ }^{1}$

A concepção de literatura como similar à pintura, cumprindo o preceito do $u t$ pictura poesis de Horácio ([1910], p. 109), repousa no princípio clássico de que a poesia deve ser uma arte mimética por excelência, ou seja, é conveniente que o poeta reproduza o mundo natural, por meio das palavras, mas procurando se utilizar de expedientes próprios dos pintores, como a enumeração de seres e objetos, a objetividade, o concretismo, a visualização, o cromatismo. Todavia, há que se observar que essa reprodução do mundo natural levará em conta não a natureza bruta em si, mas a natureza melhorada, vista em seus aspectos mais aprazíveis, para não só causar prazer no auditório, mas também para educá-lo com a visão do que é belo:

1 Professor Titular da Universidade de São Paulo (USP), Coordenador do Mestrado Interdisciplinar em Ciências Humanas da Universidade de Santo Amaro (Unisa), autor de A Estética Simbolista, Alçapão de Imagens, A Poesia como a Pintura: a ekphrasis em Albano Martins, entre outros livros. 
Os defensores da arte, clássicos e neoclássicos por igual, resolveram o problema alegando que a poesia imita não o real, mas conteúdos, qualidades, tendências ou formas seletos que estão dentro ou por detrás do real, elementos verídicos da constituição do universo, que são de valor mais alto que a realidade mesma, grosseira e indiscriminada. Ao refleti-la, o espelho posto frente à natureza reflete o que, por oposição à "natureza", os críticos ingleses amiúde chamam de "natureza melhorada", ou "realçada", ou "refinada", ou com a expressão francesa la belle nature. Esta, dizia Bateux, não é "o verdadeiro real, mas o verdadeiro possível, o verdadeiro ideal, que está representado como se existisse realmente e com todas as perfeições que pudesse receber" (ABRAMS, 1962, p. 57).

Entende-se, pelo texto acima, que os poetas devem promover uma seleção de aspectos do real, para captar tão só a sua essência, porquanto a realidade aparente é grosseira e não apresenta o necessário equilíbrio entre os seus elementos, com isso e de certa forma, deseducando o leitor desprevenido. Isso acontece devido ao fato de que a verdadeira mimesis poética

nunca foi uma cópia fiel do objecto "imitado", mas, apenas, essa "aproximação" de que já fala Platão. Para este filósofo, "o conceito flutua”, acabando por admitir, no Filebo, que "a boa mimesis" levaria o artista a aproximar-se da estrutura essencial da realidade, a qual permite fixar o que é universal e permanente (REYNAUD, 2001, p. 41).

Esse tipo de descrição que imita a pintura, por meio dos recursos pictóricos, adaptados à expressão verbal, e, ao mesmo tempo, procura reproduzir os aspectos mais positivos e aprazíveis da Natureza, pode ser vista no poema abaixo do poeta árcade Bocage (1974, p. 23-24):

Já se afastou de nós o Inverno agreste

Envolto nos seus úmidos vapores;

A fértil Primavera, a mãe das flores,

O prado ameno de boninas veste.

Varrendo os ares, o sutil Nordeste

Os torna azuis; as aves de mil cores

Adejam entre Zéfiros e Amores,

E toma o fresco Tejo a cor celeste.

Vem, ó Marília, vem lograr comigo

Destes alegres campos a beleza,

Destas copadas árvores o abrigo.

Deixa louvar da corte a vã grandeza:

Quanto me agrada mais estar contigo

Notando as perfeições da Natureza!

O poeta tem um interlocutor, sua amada Marília, chamada para o poema pelo uso do vocativo, termo sintático que, segundo Cegalla (2010, p. 367), “é 
um termo à parte. Não pertence à estrutura da oração, por isso não se anexa ao sujeito nem ao predicado". Ora, se o substantivo próprio, evocado, está fora da estrutura da oração, sintaticamente livre, a sua utilização para representar a figura da pessoa amada serve para ressaltar que ela está, por conseguinte, fora do espaço edênico pintado, ou seja, é um ser estranho a ele. Ao evocar Marília, o eu-poético, não só a chama para mundo ideal, como também, para exercer algum tipo de atração sobre a mulher, pinta uma cena bucólica, a fim de que ela possa contemplar, de maneira prazerosa, o que ainda não contempla ou não contemplou, pelo fato de ser habitante da cidade. Por meio do objeto estético, o sujeito da enunciação torna visível e vivo o que está distante e não presente aos olhos da mulher. Ele se torna, pois, o intermediário entre os olhos da amada e uma paisagem que recupera por meio dos sentidos, daí o aspecto puramente visual, concreto e sinestésico das imagens.

Isso acontece nas duas primeiras estrofes, nas quais o poeta fala do fim do Inverno e da vinda da Primavera que é, por natureza, toda feminil e cheia de graças. A oposição entre ambas as estações não se manifesta apenas no fato de o primeiro ser masculino e a segunda, feminina. Manifesta-se também pela adjetivação. Seria importante, pois, examinar a carga semântica dos termos referentes ao Inverno à Primavera:

Quadro 5.1 - Carga semântica dos termos referentes ao inverno à primavera

\begin{tabular}{c|c}
\hline Inverno & Primavera \\
\hline Agreste & Fértil \\
\hline Úmidos & Ameno \\
\hline & Sutil \\
\hline & Azuis \\
\hline & Fresco \\
\hline & Celeste \\
\hline & Alegres \\
\hline & Copadas \\
\hline
\end{tabular}

Se, no primeiro caso, há somente dois adjetivos, um deles sugerindo rudeza, aspereza e o outro, algo malsão, no segundo caso, os adjetivos, utilizados em profusão, são todos aprazíveis, indicando tranquilidade, prazer, harmonia. A escolha dos adjetivos faz reforçar essa ideia de um local magnífico, concebido segundo o tópos clássico do locus amoenus, em que tudo é belo, equilibrado, perfeito. Segundo Curtius (1996, p. 254), esse tópos 
Constitui o motivo principal de toda descrição da Natureza. [...] é uma bela e sombreada nesga da Natureza. Seus elementos essenciais são uma árvore (ou várias), uma campina e uma fonte ou regato. Admitem-se, a título de variante, o canto dos pássaros, umas flores e, quando muito, o sopro da brisa.

Vale a pena apontar ainda a presença da hipérbole em "as aves de mil cores”, que serve para acentuar o caráter excepcional do cenário, já que esta figura "consiste na ênfase resultante do exagero deliberado, quer no sentido negativo, quer no positivo" (MOISÉS, 2004, p. 223) e implica "exagerar a verdade, mas com respeito à beleza, seja por amplificação, seja por atenuação" (QUINTILIANO, 1979-1989, p. 67). O exagero da referência às cores serve para criar uma Natureza especial, que parece não ser deste mundo. Ela só se torna presente na estação dos amores que é a Primavera, momento presentificado pela enunciação.

Assim, notam-se dois tempos: o ido, representado pelo pretérito perfeito "Já se afastou" - e que se torna nebuloso, e o presente, dominante em todo o poema, em que se dá a fertilização do mundo, por meio do aparecimento das flores no campo. Na segunda estrofe, o caráter visual do soneto mais se acentua, com a referência não só às cores - o azul tanto dos céus quanto do rio, as hiperbólicas "mil cores" das aves -, mas também ao uso das personificações, que dão humanidade ao tipos de vento - o Nordeste -, a brisa - os Zéfiros -, e Amores. Nesse mundo edênico, tudo se torna concreto e visível, como numa boa pintura, em que mesmo os elementos, as entidades e/ou deidades pagãs são figuras de carne osso. O proposital uso da prosopopeia, que "consiste em atribuir vida, ou qualidades humanas, a seres inanimados, irracionais" (MOISÉS, 2004, p. 374) serve para acentuar a concretude de tudo, como se fosse possível visualizar a figura do Inverno como um velho vestindo um manto que se vai e a Primavera como uma figura feminina delicada e grávida que se perpetuará na paisagem edênica. $\mathrm{O}$ mesmo se pode dizer dos ventos fecundadores, como o Nordeste e os Zéfiros, que compartilham o espaço com os Amores alegorizados. Chama a atenção também, principalmente na segunda estrofe, o uso deliberado e sistemárico da aliteração, presente nas sibilantes, como a mimetizar o som dos ventos:

\footnotetext{
Varrendo os ares, o sutil Nordeste

Os torna azuis; as aves de mil cores

Adejam entre Zéfiros e Amores,

E toma o fresco Tejo a cor celeste.
}

Essa tentativa de apropriação dos recursos não verbais da pintura, por intermédio dos recursos verbais da poesia, nos permite cotejar o soneto de Bocage com o quadro de Botticelli, sintomaticamente intitulado A Primavera (Figura 5.1). 


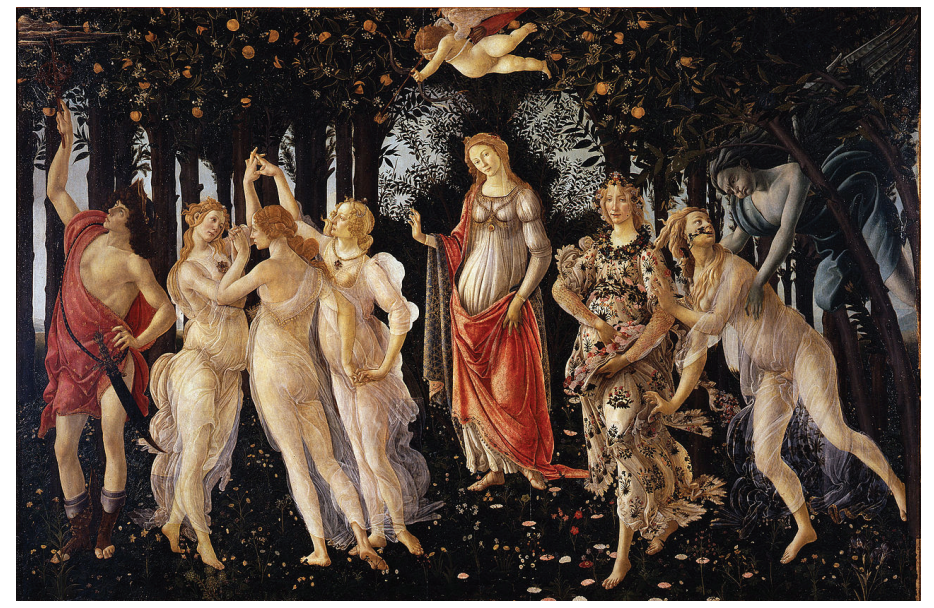

Figura 5.1 - A Primavera, de Botticelli, 1482. Fonte: Wikimedia Commons.

Na tela, a deusa Vênus, símbolo do amor, aparece centralizada e secundada, à esquerda, pelas três Graças e por Hermes, o deus mensageiro, que, indiferente aos folguedos e celebrações amorosas do mundo natural, torna-se alvo das setas de Cupido, para que também pratique a ars amatoria. Nas figuras à direita da deusa do Amor, postam-se entidades que representam o mundo floral e a sexualização da Natureza: a figura feminina coberta de flores e a mulher nua, assediada por Éolo, o deus do vento. A tela, entre outros aspectos, sugere, de modo poético, o princípio botânico da fecundação do mundo vegetal por meio da polinização, que se dá com o auxílio dos ventos. Todo alegórico, o quadro concretiza o abstrato, ao representar a fecundação da Natureza e a perfeita interação entre o mundo virginal e fresco da Primavera e o culto do Amor. É preciso acrescentar também que a tela de Botticelli pode ser lida de uma perspectiva neoplatônica, no sentido de que a contemplação do belo sensível remete ao Belo absoluto. Para tanto, é necessário, pois, que o pintor seja capaz de selecionar e descrever apenas o que há de mais perfeito na Natureza, ou seja, ele pauta-se pela representação da chamada belle nature, aquela que é uma representação pictórica e literária ao mesmo tempo. Tanto no poema quanto no quadro, há a intenção de captar não a natureza hostil e imperfeita, mas uma natureza toda idealizada. Isso implica o registro de aspectos belos apenas, selecionados pelo olhar seletivo do pintor ou do poeta, e que devem causar grande prazer aos olhos do leitor/espectador e, por conseguinte, conduzi-lo do mundo sensível ao mundo das ideias. De acordo com Nicholas Mann (2004, p. 20),

A Primavera encerra um simbolismo muito elaborado. É uma alegoria da harmonia da natureza e da civilização humana, que era um tema frequente da filosofia neoplatônica. A natureza é representada aqui pela primavera, personificada como a deusa 
romana Flora, enfeitada com flores. As três Graças, formando um arabesco à esquerda, representam a harmonia musical e, portanto, a civilização da natureza humana. Vênus, no centro do quadro, é retratada como uma madona pagã capaz de elevar a mente humana à contemplação de uma beleza divina que transcende à distinção entre natureza e civilização.

A Natureza pintada, ornamentada pelos tropos, presentifica-se e torna-se um modelo e, como tal, é que educará Marília, a começar pelos sentidos, pois ela deverá gozar de dois aspectos essenciais e inseparáveis desse mundo: a "beleza" e o "abrigo". O primeiro pertence ao plano do estético e o segundo, ao do útil, ou seja: qualquer beleza que se preze, considerada em seu valor absoluto, compreende também um aspecto utilitário. É por isso que o espaço citadino é considerado criticamente como o mundo dos excessos: a sua "grandeza", que se opõe à "beleza" da Natureza, é, ainda por cima, adjetivada por "vã”, sinônimo do que não tem utilidade. O poema, ao cabo, segue também o princípio horaciano de que os poetas devem "educar, deleitando" (HORÁCIO, [1910], p. 104). Para M. H. Abrams, esta orientação crítica, que visa a um auditório, seria denominada "teoria pragmática", na medida em que se considere "a obra de arte principalmente com um meio para um fim, como instrumento para conseguir que se faça algo, e tende a julgar seu valor caso tenha êxito para realizar esse propósito" (ABRAMS, 1962, p. 29). Para tanto, ao se utilizar do recurso retórico da apóstrofe, em que se insere uma exortação moral, o poeta deseja educar a mulher. Mas, frise-se bem: 0 preceito moral, dirigido à amada, de que o campo é melhor que a cidade, porque mais belo e útil, só comparecerá depois que se pintar a cena rupestre. Causa-se assim o deleite aos olhos com a poesia pintada, para que os pressupostos morais tenham maior efeito sobre o interlocutor.

Contudo, é preciso levar em conta que, no caso do poema, não é a Natureza em si que se apresenta aos olhos da amada e, sim, a sua recriação ecfrástica, sua pintura com palavras. Quem serve de intermediário entre Marília e o mundo natural é o eu-poético que, com o apelo do poema pintado, em que os signos verbais imitam os signos não-verbais, torna o que está distante, próximo, evidente, ao recriar com cores bem vivas um mundo ideal. A descrição, no caso, é de segundo grau, porque o poeta não representa apenas o mundo natural, mas procura imitar as técnicas descritivas próprias da pintura, ao apelar para o intenso visualismo, para a objetividade e para o cromatismo.

Em conclusão, verificamos que o uso dos adjetivos e verbos e de recursos retóricos como a personificação, a hipérbole, a aliteração, a alegoria e de topoi clássicos, como o locus amoenus, o fugere urbem, estão a serviço da montagem de um espaço ideal que será presentificado pela linguagem poética. 


\section{Referências}

ABRAMS, M. H. El espejo y la lámpara. Buenos Aires: Editorial Nova, 1962.

BOCAGE, M. M. B. du. Poemas escolhidos. São Paulo: Cultrix, 1974.

CEGALLA, D. P. Novíssima gramática da língua portuguesa. 48. ed. rev. São Paulo: Companhia Editora Nacional, 2010.

CURTIUS, E. R. Literatura europeia e Idade Média latina. São Paulo: Edusp, 1996.

HORÁCIO. Arte Poética. Lisboa: Clássica Editora, [1910].

MANN, N. Renascimento. London: Andromeda Oxford, 2004.

MOISÉS, M. Dicionário de termos literários, 12. ed. rev. e amp. São Paulo: Cultrix, 2004.

QUINTILIANO, M. F. Institutio Oratoria. Cambridge, MA: Harvard UP, 1979-1989. 4 v.

REYNAUD, M. J. Fernando Echevarría, Enigma e Transparência. Porto: Caixotim, 2001. 
